\title{
Carrillo, Ana Lorena (2009), Árbol de historias. Configuraciones del pasado en Severo Martínezy Luis Cardoza y Aragón, Guatemala: Editorial Pensativo.
}

\section{Una lectura cirujana}

E n este libro Ana Lorena Carrillo nos interioriza a dos textos emblemáticos en la reflexión guatemalteca: Guatemala, las líneas de su mano de Luis Cardoza y Aragón y La patria del criollo de Severo Martínez Peláez. Los autores comparten un momento político y social de la historia guatemalteca, aunque uno le lleve al otro algunos años de diferencia en su realización. Ambos son ensayos vistos a través del abordaje académico y literario, así como denuncias de la situación política y social guatemalteca. Contienen, pues, visibles intenciones. En ambos se recurre al pasado para explicar el presente y vislumbrar una necesaria transformación. Son miradas históricas situadas en su presente. De esta manera, la historia se convierte en la gran protagonista. A través del argumento vemos recorrer: criollos, indígenas, pueblos de indios, ciudades y paisajes, tanto coloniales como sus legados contemporáneos.

¿Pero, qué tienen en común además de ello? Ambos escritos son una combinación de mirada y escritura. Mirada del pasado asentada en escritura. Como sabemos la mirada desde lo alto y la escritura normalmente nos refieren al interés de un dominio. La mirada impuesta busca convertirse en visión. Es decir, en una verdad destinada a ser legitimada. La autora nos introduce en la forma en que Cardoza y Aragón y Martínez Peláez proyectan sus visiones, usando el pasado para denunciar el presente. El primero enfocado en la experiencia de la derrota del gobierno de Arbenz en 1954 y el segundo tiene como trasfondo el reciclaje de la lucha revolucionaria de las décadas de los años sesenta y setenta. Ambos autores usan el ensayo como instrumento de comunicación. Es decir, recurren estratégicamente al recurso reflexivo, deliberativo, interpretativo y persuasivo. Con ello continúan esa larga tradición latinoamericana donde el argumento es lo central, en el cual deliberar es demostrar. En Cardoza y Aragón predomina el discurso poético, las expresiones metafóricas y le reconocemos su erudición literaria. En Martínez Peláez predomina el discurso científico, pero también le reconocemos su pasión en el escribir. Ambos buscan tocar las teclas de la emoción, seducir con un argumento que llaman a convertirlo en un nosotros. La derrota es explicada en la necesidad de comprender la complejidad del país y en la denuncia del dominio y opresión de la herencia criolla. La pretensión es incidir en el lector: emocionarlo e indignarlo en la medida que van legitimando su intención, su verdad política, el comprender la realidad para transformarla. 
Pero, la autora no se contenta con decirnos eso, sino profundiza en su lectura. De ese modo nos recuerda que ésta última tiene un margen de acción y de libertad frente a las actividades impositivas de la escritura y la mirada. La escritura busca fijar la mirada y utiliza sus argucias para llevar al lector hacia donde quiere llevarlo. Pero en la lectura el lector, escoge, filtra, escarba, rechaza, acoge, desconfía..., y deja las puertas abiertas para escabullirse. Claro, sólo si ese lector deja de leer como creyente, aceptando el "querer decir" del autor en función de la fuerza de su autoridad. Y, así se involucra en una lectura donde predomina el "querer escuchar".

A esta altura nos damos cuenta que Ana Lorena Carrillo desarrolla una lectura cirujana. Analogía tosca pero figurativa. Ya no es una mirada desde la altura sino nos introduce en las intimidades de los dos textos. Penetra en ellos, los delimita y los secciona. Nos va presentando sus intencionalidades y la construcción de esa intencionalidad. Nos introduce en una nueva forma de leer, recorriendo las expectativas de los autores en su contexto y posibilidades, en ese horizonte de expectativas del que nos habla la autora.

Además, nos advierte que no pretende mirar el contenido sino el uso social del texto. Y, esto puede tener dos caras. La primera es cómo los autores están empapados del uso social de su tiempo. Impregnados de heterogéneas corrientes de pensamiento, recogiendo de aquí y de allá, mezclando, tejiendo y ensamblando para dotar de coherencia al argumento. Esta es la intencionalidad explícita. Pero, también es posible ver cómo lo social, a su vez, los usa. Cómo son producto de su tiempo, cómo inciden sus patrones culturales, cómo el entorno los marca, cómo el lenguaje, el relato y la narración son parte de la vida social que los envuelve. Además, nos va enseñando cómo los autores no sólo miran hacia atrás acoplando el pasado al presente, también nos muestra cómo se introducen en sus propios relatos y ese relato se convierte en el yo de ambos. Un yo que navega en el pasado emergiendo tanto la ideología como la emoción poética. Ambos transfiguran su yo en el texto y nuevamente pretenden convertirlo en un nosotros.

Poco a poco uno va metiéndose en la lectura cirujana de la autora, al grado que tenemos que frenarnos y preguntarnos: ipero quiénes son ellos y por qué transcienden? Pregunta de respiro a pesar de que hemos conocido a esos autores. No nos son extraños, los hemos leído con anterioridad. Martínez Peláez, historiador, conocido hasta la saciedad por muchos, Cardoza y Aragón, literato, conocido hasta la saciedad por otros muchos. Y, entonces nos damos cuenta que los hemos convertido en autores clásicos. Palabra que nos recuerda lo dicho por Jeffrey Alexander, quien nos explicaba que, con esa categoría nombrábamos a un rango de personajes privilegiados frente a los personajes de hoy. Al retomarlos aprendemos de ellos tanto como lo hacemos con nuestros contemporáneos. La fuerza evocativa de su discurso recae en el argumento en tanto éste se aboca en el razonamiento. De manera que, sus pretensiones de validez no se remiten a los datos que nos muestran sino a que tanto tirios y troyanos llegan a entender de lo que nos hablan. En definitiva nos facilitan la discusión y la comunicación entre heterogéneos y podemos leerlos sin necesariamente adherirnos a sus criterios. En nuestro caso, ambos autores nos delimitaban el campo del discurso político sobre el pasado. Y, entonces nos damos cuenta, que ya no sólo estamos intentando comprender la lectura que Ana Lorena Carrillo nos transmite sobre nuestros dos personajes, sino comenzamos a leerla de manera cirujana a ella también. Junto con ella releemos a esos clásicos y compartimos lo que estos tratan de comunicar y lo que ella a su vez nos comunica.

Podemos observar el uso de la ciencia que hace Martínez Peláez para sumergirnos en la intención de interpretar la patria del criollo. Vemos a su yo traer el pasado al presente y luego desplazarse en él. Reconocemos su argumento y el efecto de verdad que nos trasmite para que creamos en lo que dice. Comprendemos como el criollo construye su visión de

212 Revista LiminaR. Estudios sociales y humanísticos, año 8, vol. VIII, núm. 1, junio de 2010, San Cristóbal de Las Casas, Chiapas, México. ISSN: 1665-8027 
patria a través de su sentido de propiedad. Observamos cómo recurre a su enemigo simbólico, el criollo, para mostrar lo que éste oculta en su interés por dirigir una nación acoplada a su idea de posesión. Vemos cómo combina la emoción por la historia con la interpretación en función del cambio social. También es posible ver su arrogancia por llevar esa historia al indígena y convertirla en la historia de éste, pensando en que se dirige a un ser que recibe y reacciona pero que no actúa. A su vez, descubrimos no sólo la mezcla de las corrientes de pensamiento sino también el trasfondo liberal de su marxismo. Además, notamos el encaje del sentido popular en una dimensión social. Así, se nos va haciendo más fácil entender su denuncia y lo que debe superarse.

También vemos a Cardoza y Aragón, cuyo lenguaje abigarrado y erudito refleja su propia trayectoria, conocedor del mundo intelectual europeo y arraigado en México, un país de debate intelectual intenso. Escribe para ellos y no para el público guatemalteco en el afán de hacer comprensible el país en un marco universal. No deja de chocar en Guatemala donde es incomprendido. País de lacerante crítica hacia su intelectualismo y a su origen criollo. No obstante, su dificultad para traducirse popularmente insiste en crear un discurso nacional no nacionalista, imbuido en un romanticismo intimista: el yo que se hunde en los significados de su patria para transportarla al mundo y en una mirada apoyada en el rescate de su propia experiencia. Obviamente, en el marco de una derrota cercana y de una reflexión de poco optimismo por el futuro, pero sin abandonarlo. Observamos a un autor que mira desde arriba como universalista con su romanticismo y sensibilidad intelectual, pero también que ve desde adentro y expresa profundidad en la búsqueda íntima.
Llegado a este punto reconocemos cómo la autora nos ha transportado a través de su lectura cirujana al interior de esos textos. Y, los masticamos mejor, al mismo tiempo que nos aferramos a entender lo que quieren decir. La autora los comunica con nuestro presente y reproducimos aquellas intenciones, apoyados en que ambos confluyen en la necesidad transformadora, en la crítica del presente, en el proyecto de otra patria y en la promesa del cambio.

Pero, nuevamente la autora no se contenta con dejarnos ahí y seguimos profundizando en su lectura cirujana, desmenuzando palabras y cronotopos. Lugares, sucesos y sentimientos que nos transmiten historicidad: ciudad, paisaje, finca, pueblo de indios, volcán, plazas, puertas, orden, desorden, posesión, sufrimiento, nostalgia... En su momento nos llama la atención la centralidad de la ciudad de Antigua para ambos, representada por Martínez Peláez en el símbolo colonial de dominio y del conservadurismo contemporáneo, en lo oculto ahora explícito. Mientras Cardoza y Aragón, sin negar lo anterior, nos la expresa con mirada cariñosa y nostálgica en un paisaje emocional que busca unificar a los y las guatemaltecas. Incluso, al estar sumergidos en estos diseccionados textos nos permitimos imaginar a los dos autores ascendiendo el volcán de Agua. Al llegar a la cumbre Martínez Pelaéz, mira hacia lo lejos y dirige su vista hacia las lejanas cumbres de Huehuetenango, agregando: "he ahí la mirada del criollo, quien piensa que todo ello le pertenece". Mientras tanto, Cardoza y Aragón baja la vista y la dirige hacia su ciudad, al pie del volcán, sin mencionar palabra alguna.

Luis Pedro Taracena Arriola CIRMA, Antigua Guatemala, Guatemala, C. A. 